\title{
Outpatient Management of Oligosymptomatic Patients with respiratory infection in the era of SARS-CoV-2: Experience from rural German general practitioners
}

\author{
Simon Wernhart ${ }^{*}$ (D), Tim-Henning Förster ${ }^{1}$ and Eberhard Weihe ${ }^{2}$
}

\begin{abstract}
Background: Covid-19 is causing a pandemic and forces physicians to restructure their work. We want to share our experience in the outpatient management of potentially-infected patients with special consideration of altered national test strategies during the crisis.

Methods: We analysed patients with respiratory symptoms reporting to our three rural general practitioner (GP) offices in North Rhine-Westphalia, Germany, from 27.01-20.04.2020 ( $n=489$ from a total of 6090 patients). A history of symptoms was taken at the doorstep following a specific questionnaire. Patients with respiratory symptoms were examined in a separated isolation area, while the others were allowed to enter the office. We applied the first recommended algorithm of the German Robert Koch Institute (RKI) to test suspected patients and compared our results with an adapted, more liberal version of the RKI, which is currently applied in Germany.

Results: Eighty patients (16.36\%, mean age: 47.03 years+ - 18.08) were sent to a nasopharyngeal smear. Five patients (6.25\%) proved to be positive, four of whom had established risk factors for COVID-19. Overall, the most common symptoms were cough (83.75\%), sore throat (71.25\%), as well as myalgia and fatigue (66.25\%). The most common diagnoses were rhinopharyngitis (37.22\%) and acute bronchitis (30.27\%). A sore throat was more common in positively-tested patients (80\% vs. $12 \%$ ). Applying the first RKI test strategy yielded $6.25 \%$ of positive tests $(n=80)$, while the more liberal later RKI recommendation would have achieved $1.36 \%$ positive tests from 369 patients. No positive test was missed by applying the conservative strategy. None of our employees called in sick during this period, which emphasises the efficacy and safety of our screening methods.

(Continued on next page)
\end{abstract}

\footnotetext{
* Correspondence: simon.wernhart@gmx.de

'Sauerlandpraxis Medebach-Hallenberg-Winterberg, Niederstrasse 2, 59964 Medebach, Germany

Full list of author information is available at the end of the article
}

(C) The Author(s). 2020 Open Access This article is licensed under a Creative Commons Attribution 4.0 International License, which permits use, sharing, adaptation, distribution and reproduction in any medium or format, as long as you give appropriate credit to the original author(s) and the source, provide a link to the Creative Commons licence, and indicate if changes were made. The images or other third party material in this article are included in the article's Creative Commons licence, unless indicated otherwise in a credit line to the material. If material is not included in the article's Creative Commons licence and your intended use is not permitted by statutory regulation or exceeds the permitted use, you will need to obtain permission directly from the copyright holder. To view a copy of this licence, visit http://creativecommons.org/licenses/by/4.0/ The Creative Commons Public Domain Dedication waiver (http://creativecommons.org/publicdomain/zero/1.0/) applies to the data made available in this article, unless otherwise stated in a credit line to the data. 


\begin{abstract}
(Continued from previous page)
Conclusion: A clinical distinction between ordinary respiratory infections and COVID-19 is not possible in a lowprevalence population. Our model to prevent unprotected physical contact, screen patients in front of the office with protective equipment, and examine respiratory infections in separated areas works in the GP setting without overt health risks for employees. Thus, this approach should be used as a GP standard to uphold patient care without major health risks for the personnel. Large multi-centre studies are necessary to work out the most suitable test strategy.
\end{abstract}

Keywords: General practitioner, COVID-19, Test strategy

\section{Background}

Originating from Wuhan, China, Corona Virus Disease 2019 (COVID-19) has spread around the world as a pandemic and created enormous health, political, and economic problems [1, 2], with more than 18 million confirmed cases worldwide and more than 700,000 deaths as of 07.08.2020 [3].

Clinical predictors of mortality have been suggested from a cohort of patients from Wuhan [4-6] and recommendations for outpatient [7] and inpatient care [6] as well as intensive care treatment [8] have been proposed. Patients admitted to intensive care units are older, and tend to have higher leukocyte counts, D-Dimers, LDH, creatinine, and troponin levels [5]. Elevated troponin as a marker for myocardial injury heralds a poor prognosis [9].

The most common symptoms - depending on the time window during the course of infection - are symptoms associated with respiratory diseases, such as fever, cough, sore throat, headache, chills, fatigue and myalgia, smell and taste dysfunction and gastrointestinal problems [10, 11 ], but recently more severe cases have been associated with neurological symptoms, such as acute cerebral vascular disease, skeletal muscle injury and impaired consciousness [12]. Perniosis-like skin symptoms may also be present $[13,14]$. Risk factors for more severe cases of COVID-19 are hypertension, coronary artery disease, immunosuppression, and chronic lung disease [15].

Less severe cases often present to the general practitioner (GP) in the outpatient setting, which requires precautions to avoid infection among medical staff. In Germany, testing for SARS-CoV-2 infection has been widely established $[16,17]$. Additionally, containment as a means to reduce exponential growth has been implemented at an early stage [18], which may account for the relatively low German case mortality rate in March and April 2020 (4.1\%) compared with other European countries [19, 20]. As of 07.08.2020, in Germany more than 200,000 patients had been infected and more than 9000 had died [3]. Furthermore, standard and elective examinations have been postponed to limit physical physicianpatient contact to the necessary minimum [21].

The German government as well as national and federal medical institutions have made considerable efforts to prevent less critical but potentially infectious patients from showing up in the GP office by installing telephone and video conference facilities to provide medical council without physical contact. However, in practice concerned patients who fear that they are infected keep showing up and need to be screened in isolation rooms in case of symptoms suggestive of COVID-19. This requires office re-organisation and efforts to obtain personal protective equipment (PPE), albeit which has been difficult to access for some time.

The German Robert Koch Institute (RKI) has issued recommendations for COVID-19 screening in the outpatient setting [22]. However, a differentiation between oligosymptomatic COVID-positives and ordinary infections seems almost impossible. Here, we present real-life data from our three large rural GP offices in North Rhine-Westphalia, Germany, between 27.01 and 20.042020 to demonstrate the difficulty of filtering oligosymptomatic patients with low pre-test probability. Our aim is to share our experience as GPs with colleagues from other countries, where infection rates may be even higher and viral doubling time is very low.

\section{Methods}

We analysed data from our three GP offices in rural North Rhine-Westphalia, Germany, from 27.01.2020 until 20.04.2020 and selected all patients reporting symptoms of respiratory tract infection. According to the RKI guidelines during the study period to screen patients for potential COVID-19 infection (Fig. 1), we chose to either send patients to a nasopharyngeal smear or treat them conservatively. Due to the limited availability of smear testing in our rural area at that time, we were unable to perform the smears in our offices, but had to transfer patients to the local hospital. Patients were put into quarantine until the results of the tests were available. We have gained satisfactory experience with the following procedures and algorithm at the onset of the pandemic in Germany: one GP with PPE comprising a gown, goggles, caps, gloves and an FFP (filtering face piece)-3 mask screens every patient in front of our office, asking the following questions: 


\section{Consider a smear, if any of the following applies:}

-> Unspecific general symptoms or acute respiratory symptoms of any severity AND contact with a patient who has tested positive for COVID-19 within 14 days of symptom onset.

$\rightarrow$ Acute respiratory symptoms of any severity with or without fever AND stay in risk areas within 14 days of symptom onset.

-> Acute respiratory symptoms of any severity with or without fever AND stay in areas with positively- tested patients until 14 days before the onset of symptoms.

-> Clinical or radiological suspicion for viral pneumonia without an alternative diagnosis AND no evident risk of COVID-19 exposure.

Fig. 1 First test criteria of the RKI. SARS-CoV-2 test criteria of the German Robert Koch Institute as of March 2020

(1) Are you currently suffering from a cough or sore throat?

(2) Have you measured a temperature $>38.5$ degrees Celsius in the last five days?

(3) Have you had direct contact with a person who has tested positive for COVID-19?

(4) Are you employed in a medical profession?

(5) Are you suffering from a loss of smell or taste?

(6) Are you suffering from myalgia, fatigue or headache?

(7) Are you suffering from diarrhoea or vomiting?

(8) Are you suffering from immunosuppressive disease?

If two of these questions were answered with yes, patients were directed to an isolation room, which was supplied with all basic medical devices to provide a fast clinical exam. Patient history was documented vigorously. In case of persisting suspicion following the diagnostic algorithm of the RKI for COVID-19 [22], patients were directly referred to our smear centre. If an ordinary respiratory infection was given as a diagnosis, people were instructed on general hygiene recommendations and treated conservatively. Only patients with symptoms not suggestive of respiratory disease were allowed to enter the regular office.

There was a change in RKI guidelines on how to screen outpatient contacts after the end of our study
(Fig. 2). We therefore calculated the number of recommended smears for the first and modified RKI guidelines.

\section{Results}

The mean age of all tested patients $(n=80)$ was 47.03 years +-18.08 (mean age of positively tested, 50.20 years $+13.76 ; n=5$ ), while the mean age of all symptomatic patients $(n=489)$ was 52.69 years +-14.75 . Symptoms across all respiratory infections are provided in Table 1, while Fig. 3 illustrates the data collection. $13.75 \%$ of patients with respiratory tract infections were recent returners from (at that time) risk areas of transmission defined by the RKI (mainly from Austria and the Netherlands). $8.75 \%$ had had significant (at least 15 min) contact with a person who had tested positive for COVID-19.

Table 1. Symptoms associated with respiratory tract infection between 27.01.2020 and 20.04.2020 in all patients $(n=489)$, those negatively tested $(n=75)$ and positively tested $(n=5)$.

By far the most common diagnoses among the entire patient population were rhinopharyngitis and acute bronchitis, while pneumonia was less commonly found (Table 2). Due to the low number of positive tests, we did not perform mean comparison tests, and data were depicted as absolute values and percentages.

Take a smear, if any of the following applies:

-> Acute respiratory symptoms of any severity and/or loss of taste/smell in ALL patients, regardless of risk factors.

$\rightarrow$ Contact with positive COVID-19 cases within a maximum of 14 days before symptom onset AND any symptoms potentially associated with COVID-19, such as: cough, fever, rhinitis, anosmia, loss of taste, pneumonia, sore throat, dyspnea, headache, loss of appetite, weight loss, nausea, stomach ache, vomiting, diarrhea, conjunctivitis, exanthema, swelling of lymph nodes, apathy and somnolence.

$\rightarrow$ Clinical and radiological suspicion of viral pneumonia AND association with a clustering of pneumonia in hospitals or nursing facilities.

Fig. 2 Modified test criteria of the RKI. SARS-CoV-2 test criteria of the German Robert Koch Institute as of August 2020 
Table 1 Symptoms of patients with respiratory tract infections

\begin{tabular}{lll}
\hline Symptoms in all patients $(\boldsymbol{n}=\mathbf{4 8 9})$ & Symptoms: negatively tested $(\boldsymbol{n}=\mathbf{7 5})$ & Symptoms: positively tested $(\boldsymbol{n}=\mathbf{5})$ \\
\hline Cough $n=407(83.23 \%)$ & Cough $n=63(84.00 \%)$ & Cough $\mathrm{n}=4(80.00 \%)$ \\
Sore throat $n=70(14.35 \%)$ & Sore throat $n=9(12.00 \%)$ & Sore throat $\mathrm{n}=4(80.00 \%)$ \\
Myalgia and fatigue $n=309(63.19 \%)$ & Myalgia and fatigue $n=50(66.67 \%)$ & Myalgia and fatigue $n=3(60.00 \%)$ \\
Headache $n=158(32.31 \%)$ & Headache $n=22(29.33 \%)$ & Headache $n=2(40.00 \%)$ \\
Rhinitis $n=245(50.10 \%)$ & Rhinitis $n=20(26.67 \%)$ & Rhinitis $n=3(60.00 \%)$ \\
Fever $>38.5$ degree Celsius $n=70(14.31 \%)$ & Fever $>38.5$ degree Celsius $n=9(12.00 \%)$ & Fever $>38.5$ degree Celsius $n=1(20.00 \%)$ \\
Smell and taste dysfunction $n=51(10.43 \%)$ & Smell and taste dysfunction $n=9(12.00 \%)$ & Smell and taste dysfunction $n=0(0.00 \%)$ \\
Chills $n=69(14.11 \%)$ & Chills $n=8(10.67 \%)$ & Chills $n=1(20.00 \%)$ \\
Earache $n=41(8.38 \%)$ & Earache $n=4(5.33 \%)$ & Earache $n=0(0.00 \%)$ \\
\hline
\end{tabular}

Table 2. Distribution of diagnoses in all patients reporting with signs of respiratory infection $(n=489)$, those negatively tested $(n=75)$ and positively tested $(n=$ 5) between 27.01.2020 and 20.04.2020. A diagnosis of pneumonia was established in case of significant auscultation and one additional symptom, such as fever or productive sputum. Chest X-ray was not available.

Among 80 patients who met the first (Fig. 1) RKI criteria [22] and were sent to the smear centre, only five proved to be positive. The most common symptoms in positive patients were cough (4/5), sore throat (4/5), myalgia and fatigue (3/5) and rhinitis (3/5). Headache $(2 / 5)$, chills $(1 / 5)$ and fever $(1 / 5)$ were less common. None of these positively-tested patients suffered from smell or taste dysfunction or ear ache. According to the modified RKI criteria (Fig. 2), we would have sent 369 patients to the smear centre $(75.46 \%)$, also gaining five positive test results $(1.36 \%)$. During the study period, we did not

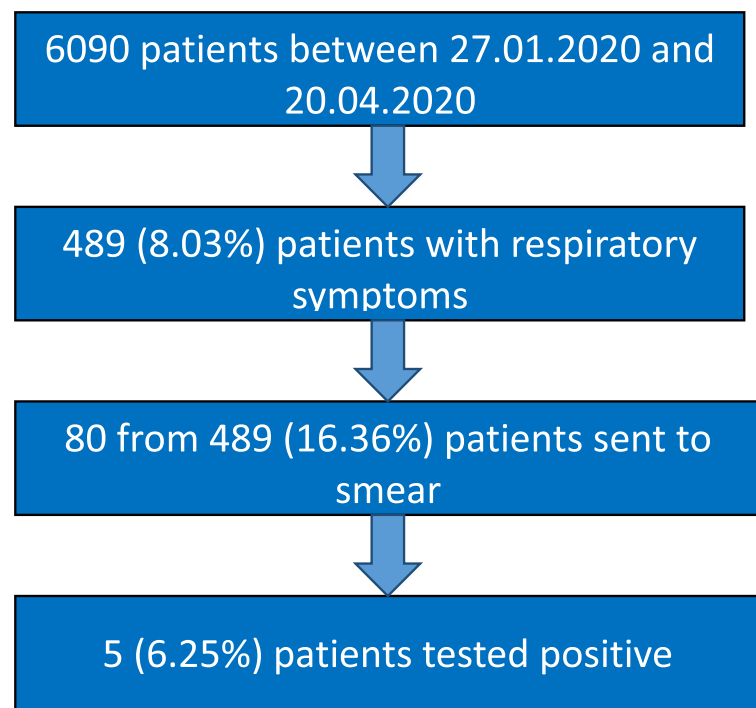

Fig. 3 Data collection. Description of the process of data collection (percentages shown in parentheses) experience any patients who were not sent for a smear first but were tested positive later on.

Table 3 illustrates the comorbidities of positively- and negatively-tested patients. In both groups, no skin alterations were detected.

Table 3. Prevalence of comorbidities in patients tested positive $(n=5)$ and negative $(n=75)$ for COVID-19. Immunosuppression was defined as autoimmune disease or cancer in patient history. Lung disease was defined as chronic obstructive lung disease or asthma under medical treatment. Chronic kidney disease was defined as a glomerular filtration rate (GFR) $<60 \mathrm{ml} / \mathrm{min}$ for at least three months. Oral anticoagulants included vitamin $\mathrm{K}$ antagonists (VKA) and new oral anticoagulants (NOAK.), platelet inhibitors included Aspirin, Clopidogrel, Ticagrelor or Prasugrel. RAAS inhibitors: reninangiotensin-aldosterone system inhibitors.

\section{Discussion}

We analysed data from our three GP offices in rural Germany between the onset of Covid-19 in our country on 27.01.2020 until 20.04.2020. The mean age of our patients was 47.03 years, which is quite young considering that mortality seems to increase in COVID-19 patients beyond 65 years, while patients younger 65 with minimal predisposing factors may be at a low risk of severe disease [5].

Only five out of 80 tested patients were positive for SARS-CoV-2 (positives). Due to this low number and a potential reporting bias of symptoms, we refrained from using mean comparison tests and only depicted absolute values. However, we noticed that almost all patients in the positively-tested group suffered from a sore throat $(4 / 5 ; 80 \%)$, while only $12 \%$ in the negatively-tested group (negatives) showed this symptom (9/75). Furthermore, rhinitis was more prominent in the positively-tested group (60\% vs. $26.67 \%$ ). Due to the limited case number, generalisability of these findings is not possible.

Known comorbidities - especially pre-existing lung and cardiovascular disease - in positively- and negatively-tested group were quite low (see Table 3). 
Table 2 Diagnoses of patients reporting with respiratory tract infections

\begin{tabular}{lll}
\hline Diagnosis in all patients $(\boldsymbol{n}=\mathbf{4 8 9})$ & Diagnosis: $\mathbf{n e g a t i v e l y}$ tested $(\boldsymbol{n}=\mathbf{7 5})$ & Diagnosis: positively tested $(\boldsymbol{n}=\mathbf{5})$ \\
\hline Rhinopharyngitis: $n=182(37.22 \%)$ & Rhinopharyngitis $n=23(30.67 \%)$ & Rhinopharyngitis $n=2(40 \%)$ \\
Acute bronchitis $n=148(30.27 \%)$ & Acute bronchitis $n=25(33.33 \%)$ & Acute bronchitis $n=3(60 \%)$ \\
Acute sinusitis $n=52(10.64 \%)$ & Acute sinusitis $n=19(25.33 \%)$ & Acute sinusitis $n=0(0 \%)$ \\
Tonsillitis $n=34(6.95 \%)$ & Tonsillitis $n=3(4.00 \%)$ & Tonsillitis $n=0(0 \%)$ \\
Otitis media $n=34(6.95 \%)$ & Otitis media $n=2(2.67 \%)$ & Otitis media $n=0(0 \%)$ \\
Pneumonia $n=31(6.33 \%)$ & Pneumonia $n=3(4.00 \%)$ & Pneumonia $n=0(0 \%)$ \\
Laryngitis $n=8(1.64 \%)$ & Laryngitis $n=0(0 \%)$ & Laryngitis $n=0(0 \%)$ \\
\hline
\end{tabular}

The most common cardiovascular risk factor was arterial hypertension, which has already been published [5]. SARS-CoV-2 uses ACE-2 as a cellular entry point [23] and has raised concerns about the continuation of RAAS inhibitor intake in patients with chronic heart failure [24]. However, recent data has shown that there is no evidence of increased disease severity or mortality in hospitalised patients on RAAS blockers $[25,26]$. Additionally, pharmacological data suggests that ACE-2 expression is not increased in patients on RAAS blockers [27]. Thus, current recommendations support the continuation of RAAS blockers in patients with arterial hypertension and chronic heart failure [24]. In our study, two out of five positivelytested patients were on RAAS blockers and did not display more severe symptoms than the others. Moreover, among the negatively-tested group RAAS blockers were the most commonly-prescribed antihypertensive drugs (15 out of 23 patients received RAAS blockers), showing no difference in clinical severity.

Table 3 Prevalence of comorbidities in patients tested for SARS-CoV-2

\begin{tabular}{|c|c|}
\hline Tested positive & Tested negative \\
\hline Diabetes: $n=2$ (40.00\%) & Diabetes: $n=2$ (2.67\%) \\
\hline $\begin{array}{l}\text { Arterial hypertension: } \mathrm{n}=3 \\
(60.00 \%)\end{array}$ & $\begin{array}{l}\text { Arterial hypertension: } n=23 \\
(30.67 \%)\end{array}$ \\
\hline Hypothyroidism: $\mathrm{n}=0$ (0\%) & Hypothyroidism: $n=11$ (14.67\%) \\
\hline $\begin{array}{l}\text { Immunosuppression: } \mathrm{n}=1 \\
(20.00 \%)\end{array}$ & Immunosuppression: $n=6(8.00 \%)$ \\
\hline Atrial fibrillation: $n=1$ (20.00\%) & Atrial fibrillation: $n=5$ (6.67\%) \\
\hline Coronary artery disease: $n=0(0 \%)$ & $\begin{array}{l}\text { Coronary artery disease: } n=3 \\
(4.00 \%)\end{array}$ \\
\hline Lung disease: $\mathrm{n}=2$ (40.00\%) & Lung disease: $n=10$ (13.33\%) \\
\hline Depression: $n=1$ (20.00\%) & Depression: $n=11$ (14.67\%) \\
\hline Chronic kidney disease: $\mathrm{n}=0$ (0\%) & $\begin{array}{l}\text { Chronic kidney disease: } \mathrm{n}=2 \\
(2.67 \%)\end{array}$ \\
\hline RAAS inhibitors: $n=2$ (40.00\%) & RAAS inhibitors: $n=15$ (20.00\%) \\
\hline $\begin{array}{l}\text { Oral anticoagulation: } n=1 \\
(20.00 \%)\end{array}$ & Oral anticoagulation: $n=5(6.67 \%)$ \\
\hline Platelet inhibitors: $n=1$ (20.00\%) & Platelet inhibitors: $\mathrm{n}=1$ (1.33\%) \\
\hline
\end{tabular}

We applied the first algorithm (Fig. 1) provided by the RKI [22] to decide which patients needed a smear. $6.25 \%$ of the tested patients were positive. This algorithm was introduced at the beginning of the crisis, during a time when travel restrictions had not been implemented across Europe. There was limited knowledge on the diversity of symptoms associated with SARS-CoV-2 at the time, and therefore unspecific respiratory symptoms alone did not qualify to send a patient to a smear centre. Travelling to a risk area and contact with positively-tested patients were important criteria in the first RKI definition.

Schmithausen et al. found that early temporary loss of taste and smell occurred in 68\% of oligosymptomatic patients who tested positive for SARS-CoV-2 after a cluster outbreak at a carnival celebration in North RhineWestphalia, Germany, less than $100 \mathrm{~km}$ away from our offices [28]. Similar to our study (80\%), the most common symptom was a dry, non-productive cough $(73 \%)$. Consequently, the RKI adapted their recommendation for SARS-CoV-2 diagnostics (after the end of our study) and implemented loss of taste and smell as a paramount factor into their algorithm (Fig. 2). It should be noted that acute respiratory symptoms of any severity now qualify to take a smear, and thus the number of smears will increase. In our population, this adapted RKI algorithm would have detected all five positive patients, but it would have also produced a much larger number of tested individuals $(n=369)$ and significantly higher costs for local health authorities. $1.36 \%$ of tested patients would have been positive, as opposed to $6.25 \%$ following the first RKI recommendations. Additionally, due to a reliable recall system from our offices, the clinic with the smear centre, and the health department, we were able to confirm that none of the patients who tested negative for SARS-CoV-2 subsequently tested positive at a later stage during the study period. This might suggest that the more conservative first RKI algorithm would have been sufficient in our low-prevalence population and the adapted, more liberal algorithm may have led to overtesting and higher costs. Our five patients who tested positive were kept in quarantine for two weeks, by when 
their symptoms had subsided. Therefore, further transmission after release is highly unlikely.

During our study, initial national efforts were devoted to measures to make testing available to everyone, especially in rural areas such as ours. During the study period, we had to send all patients to the local smear centre, which changed in May 2020 when we started performing smears directly in our offices.

A more focused approach of smear-taking has been used since the advent of clustered outbreaks [28], with a large number of positive tests along with a very low number of positive tests, such as in our area. The debate on the ideal smear strategy is ongoing. Our data contributes essential input to this debate because we can show that intensifying the smear strategy - as was done by the German RKI - does not yield a better detection of positive cases in low-prevalence populations. Perhaps algorithms have to be adapted to the federal or even local prevalence as well as regional cluster outbreaks. A very liberal strategy also binds human resources in the GP offices, which can create new problems.

Another issue that has not been entirely solved is sequential testing: a median incubation period of five days was estimated [29], which involves the danger that a negative test during early infection may pretend a false safety. Sequential testing may circumvent this, but was not applicable in our study.

In Germany, we have a health system based on solidarity, in which most people have health insurance and thus have easy access to health care. As the first medical contacts, GPs have to filter many patients directly in the office. The Center for Disease Control (CDC) has issued similar recommendations for the public as the RKI in Germany, namely (1) to cover one's own mouth and nose with a cloth, (2) call the GP's office first instead of showing up directly, (3) avoid entering into close physical contact with others, (4) engage in regular disinfection of one's hands and surfaces, (5) and self-monitor symptoms [30]. The paramount aim of medical personnel in this crisis is to maintain optimal medical care and personal health in a high-risk environment. Thus, stringent algorithms for GPs and other medical specialties need to be introduced to achieve this goal. By segregating patients who are suggestive of respiratory infection and treating them under high standards of hygiene and protection, we believe that we have achieved this goal in a practicable and efficient manner. None of our employees called in sick during the study period, which may suggest that our stringent selection process prior to entering the office is a success. Our GP experience could now help colleagues in other countries with a later onset of COVID-19 than Germany to organise their offices with the available resources. The transparency of strategies from different countries on how to deal with COVID-19 in inpatient and ambulatory settings holds paramount importance to optimise further patient care and improve educational measures [31].

Our data shows that it is not possible to accurately differentiate between oligosymptomatic COVID-19 patients and ordinary respiratory infection by analysing symptoms alone. Recently, Arons et al. published about the spread of COVID- 19 in a US nursing home, in which more than half of positively-tested patients were asymptomatic $[32,33]$. This clearly demonstrates that strategies focusing only on symptoms fail to prevent further transmission.

There is a conceivable limitation to our study: although we have investigated a large number of patients, we live in a low-prevalence area, which excludes inductive statistics and allows only a description of data. The validity of both suggested algorithms from the RKI has to be analysed in a larger and more diverse cohort. Large, prospective, randomised multi-centre trials will be necessary to ascertain the most suitable test strategy.

To sum up, our study illustrates that the application of the modified and more liberal RKI algorithm (Fig. 2) to filter patients with minor respiratory tract infections in the GP office in a low-prevalence area would lead to more (negative) testing than the first, more conservative version (Fig. 1). Different results may be gained in highrisk areas. We did not observe a conceivable difference in symptoms between COVID-19 patients and patients with ordinary respiratory tract infection. Our study also adds valuable information to the literature on how to practically manage patient care in a GP office during the peak of the COVID crisis in Germany in 2020. Additionally, we would suggest integrating working in a high-risk profession (such as hospitals or nursing homes) as a factor for future risk assessment scores for COVID-19 infections. Furthermore, as an easily-available tool in outpatient care, lung ultrasound could help to better detect COVID-19, since it has been shown that B-lines - a typical sonographic sign of pneumonia - are present at an early stage of the disease [34].

\section{Conclusion}

In summary, we provide real-life data from rural GP offices in Germany demonstrating the difficulty of distinguishing oligosymptomatic COVID-19 patients from ordinary respiratory tract infection. We provide a wellworking example on how to re-organise a GP's office to separate potentially infectious patients from the rest with minimal risk of further spreading the disease.

\section{Abbreviations}

ACE-2: Angiotensin converting enzyme; CDC: Center for Disease Control; COVID-19: Corona Virus Disease 2019; FFP-3: Filtering face piece; GFR: Glomerular filtration rate; GP: General practitioner; PPE: Personal protective equipment; RAAS: Renin-angiotensine-aldosterone system; 
RKI: Robert Koch Institute; SARS-CoV-2: Severe acute respiratory syndromeCorona virus 2; VKA: Vitamin $\mathrm{K}$ antagonist

\section{Acknowledgments}

Not applicable.

\section{Authors' contributions}

All authors read and approved the final manuscript. SW coined the idea to systematically analyse symptoms and risk factors of patients with potential COVID-19. He created the risk score, wrote the manuscript (together with EW) and performed the systematic analysis of data. TF collected the data from all offices and was responsible for the compilation of the database. EW had the idea to integrate ultrasound as a modality into our score, meticulously analysed the literature and wrote the manuscript (together with SW).

\section{Authors' information}

SW is a preventive cardiologist who focuses on primary and secondary disease prevention, he has profound experience in the intensive care management of cardiological and pneumological patients and is an active emergency doctor. He is currently employed in the GP's office. Due to his vast experience in both inpatient and outpatient management, he analysed the COVID-19 crisis in our area from a clinical and ambulatory perspective. EW is a professor of anatomy and cell biology, whose main focus of science is to explore neuroimmune and complement activation mechanisms of neurocardiovascular diseases and neurotropic virus infections. EW provided basic scientific background to compile this paper. TF is the head of all of our GP offices and has a long-lasting experience in the administration and care of ambulatory patients. After onset of the crisis in Germany, he rapidly designed a working schedule for our offices to combine patient care and safety for medical personnel. The fact that none of our personnel have developed symptoms thus far is mainly due to his foresighted thinking.

\section{Funding}

There was no funding to this study.

The results have not been presented elsewhere.

\section{Availability of data and materials}

The datasets analysed during the current study are not publicly available, but will be made available from the corresponding author on reasonable request.

\section{Ethics approval and consent to participate}

No ethics committee was involved in the study. As of 16.10.2020, according to federal regulations and law (§ 15) of North-Rhine Westphalia, Germany (https://www.recht.nrw.de//mi/owa/br_text_anzeigen?v id =741201704 06111640601\#: :text=(1)\%20\%C384rztinnen20und\%20\%C384rzte20\%C3\% BCben,Befolgung\%20sie\%20nicht\%20verantworten\%20 k\%C3\%B6nnen.), epidemiological research need not be submitted to the local ethics committee of the medical faculty Münster, Germany.

This was no clinical trial according to WHO definitions, data analysis was conducted according to WHO guidelines (https://www.who.int/about/ethics/ code-of-conduct-for-responsible-research). Data collection and analysis were performed anonymously. All patients or their legal guardians have signed a form that their results may be used for medical purposes and analyses.

\section{Consent for publication}

Not applicable.

\section{Competing interests}

The authors declare that they have no competing interests.

\section{Author details}

'Sauerlandpraxis Medebach-Hallenberg-Winterberg, Niederstrasse 2, 59964 Medebach, Germany. ${ }^{2}$ Institute of Anatomy and Cell Biology of the Philipps-University Marburg, 35037 Marburg, Germany.
Received: 2 May 2020 Accepted: 22 October 2020 Published online: 06 November 2020

\section{References}

1. Liu Y, Gayle AA, Wilder-Smith A, Rocklov J, et al. J Travel Med. 2020;27(2):14. https://doi.org/10.1093/jtm/taaa021.

2. Phelan AL, Katz R, Gostin LO. The novel coronavirus originating in Wuhan. Challenges for Global Health Governance. Jama: China; 2020.

3. Johns Hopkins University Medicine. Coronavirus Resource Center [Available from: https://coronavirus.jhu.edu/. Accessed 5 Oct 2020.

4. Ruan Q, Yang K, Wang W, Jiang L, Song J. Clinical predictors of mortality due to COVID-19 based on an analysis of data of 150 patients from Wuhan. Intensive Care Med: China; 2020

5. Wang D, Hu B, Hu C, Zhu F, Liu X, Zhang J, et al. Clinical Characteristics of 138 Hospitalized Patients With 2019 Novel coronavirus-infected pneumonia in Wuhan, China. JAMA. 2020;323(11):1061-69. https://doi.org/10.1001/jama. 2020.1585.

6. Zhou F, Yu T, Du R, Fan G, Liu Y, Liu Z, et al. Clinical course and risk factors for mortality of adult inpatients with COVID-19 in Wuhan, China: a retrospective cohort study. Lancet. 2020;395(10229):1054-62.

7. Guo F, Du Z, Wang T. An effective screening and management process in the outpatient clinic for patients requiring hospitalization during the COVID19 pandemic. J Med Virol. 2020.

8. Kluge S, Janssens U, Welte T, Weber-Carstens S, Marx G, Karagiannidis C. German recommendations for critically ill patients with COVID19. Med Klin Intensivmed Notfmed. 2020;115(3):175-177. https://doi.org/10.1007/s00063020-00674-3.

9. Tersalvi G, Vicenzi M, Calabretta D, Biasco L, Pedrazzini G, Winterton D. Elevated troponin in patients with coronavirus disease 2019 (COVID-19): possible mechanisms. J Card Fail. 2020.

10. Huang C, Wang Y, Li X, Ren L, Zhao J, Hu Y, et al. Clinical features of patients infected with 2019 novel coronavirus in Wuhan. China Lancet. 2020;395(10223):497-506.

11. Xydakis MS, Dehgani-Mobaraki P, Holbrook EH, Geisthoff UW, Bauer C, Hautefort C, et al. Smell and taste dysfunction in patients with COVID-19. Lancet Infect Dis. 2020;20(9):1015-16. https://doi.org/10.1016/S14733099(20)30293-0.

12. Mao L, Jin H, Wang M, Hu Y, Chen $S$, He Q, et al. Neurologic manifestations of hospitalized patients with coronavirus disease 2019 in Wuhan, China. JAMA Neurol. 2020;77(6):683-90. https://doi.org/10.1001/jamaneurol.2020. 1127.

13. Tammaro A, Adebanjo GAR, Parisella FR, Pezzuto A, Rello J. Cutaneous manifestations in COVID-19: the experiences of Barcelona and Rome. J Eur Acad Dermatol Venereol. 2020;34(7):e306-7. https://doi.org/10.1111/jdv. 16530.

14. Recalcati S, Barbagallo T, Frasin LA, Prestinari F, Cogliardi A, Provero MC, et al. Acral cutaneous lesions in the time of COVID-19. J Eur Acad Dermatol Venereol. 2020:34(8):e346-7. https://doi.org/10.1111/jdv.16533.

15. Kreutz R, Algharably EAE, Azizi M, Dobrowolski P, Guzik T, Januszewicz A, et al. Hypertension, the renin-angiotensin system, and the risk of lower respiratory tract infections and lung injury: implications for COVID-19. Cardiovasc Res. 2020;116(10):1688-99. https://doi.org/10.1093/cvr/cvaa097.

16. Corman VM, Landt O, Kaiser M, Molenkamp R, Meijer A, Chu DK, et al. Detection of 2019 novel coronavirus (2019-nCoV) by real-time RT-PCR. Euro Surveill. 2020;25(3):1-8. https://doi.org/10.2807/1560-7917.ES.2020.25.3.2000045.

17. Reusken C, Broberg EK, Haagmans B, Meijer A, Corman VM, Papa A, et al. Laboratory readiness and response for novel coronavirus (2019-nCoV) in expert laboratories in 30 EU/EEA countries, January 2020. Euro Surveill. 2020; 25(6):1-6. https://doi.org/10.2807/1560-7917.ES.2020.25.6.2000082.

18. Maier BF, Brockmann D. Effective containment explains subexponential growth in recent confirmed COVID-19 cases in China. Science. 2020; 368(6492):742-6. https://doi.org/10.1126/science.abb4557.

19. Konrad R, Eberle U, Dangel A, Treis B, Berger A, Bengs K, et al. Rapid establishment of laboratory diagnostics for the novel coronavirus SARS-CoV2 in Bavaria, Germany, February 2020. Euro Surveill. 2020;25(9):1-5. https:// doi.org/10.2807/1560-7917.ES.2020.25.9.2000173.

20. Stafford N. Covid-19: why Germany's case fatality rate seems so low. Bmj. 2020:369:m1395.

21. Dorr R. Protecting patients and healthcare personnel from COVID-19: considerations for practice and outpatient care in cardiology. Herz. 2020; 45(4):319-20. https://doi.org/10.1007/s00059-020-04922-2. 
22. Robert Koch Institut. [Available from: https:/www.rki.de/DE/Home/ homepage_node.html. Accessed 5 Oct 2020.

23. Liu Z, Xiao X, Wei X, Li J, Yang J, Tan H, et al. Composition and divergence of coronavirus spike proteins and host ACE2 receptors predict potential intermediate hosts of SARS-CoV-2. J Med Virol. 2020;92(6):595-601. https:// doi.org/10.1002/jmv.25726.

24. Ganatra S, Hammond SP, Nohria A. The novel coronavirus disease (COVID19) threat for patients with cardiovascular disease and Cancer. JACC CardioOncol. 2020;2(2):350-55. https://doi.org/10.1016/j.jaccao.2020.03.001.

25. Li J, Wang X, Chen J, Zhang H, Deng A. Association of renin-angiotensin system inhibitors with severity or risk of death in patients with hypertension hospitalized for coronavirus disease 2019 (COVID-19) infection in Wuhan, China. JAMA Cardiol. 2020;5(7):825-30. https://doi.org/10.1001/jamacardio. 2020.1624.

26. Mancia G, Rea F, Ludergnani M, Apolone G, Corrao G. Renin-angiotensinaldosterone system blockers and the risk of Covid-19. N Engl J Med. 2020; 382(25):2431-40. https://doi.org/10.1056/NEJMoa2006923.

27. Sriram K, Insel PA. Risks of ACE inhibitor and ARB usage in COVID-19: evaluating the evidence. Clin Pharmacol Ther. 2020;108(2):236-41. https:// doi.org/10.1002/cpt.1863.

28. Schmithausen RM, Döhla M, Schößler H, Diegmann C, Schulte B, Richter E, et al. Characteristic temporary loss of taste and olfactory senses in SARSCoV-2-positive-individuals with mild symptoms. Pathog Immun. 2020;5(1): $117-20$

29. Lauer SA, Grantz KH, Bi Q, Jones FK, Zheng Q, Meredith HR, et al. The incubation period of coronavirus disease 2019 (COVID-19) from publicly reported confirmed cases: estimation and application. Ann Intern Med. 2020;172(9):577-82. https://doi.org/10.7326/M20-0504.

30. Prevention CfDCa. Corona Virus Disease 2019 (COVID-19). How to protect yourself \& others. [Available from: https://www.cdc.gov/coronavirus/2019ncov/prevent-getting-sick/prevention.html. Accessed 5 Oct 2020.

31. Fiorino G, Colombo M, Natale C, Azzolini E, Lagioia M, Danese S. Clinician education and adoption of preventive measures for COVID-19: a survey of a convenience sample of general practitioners in Lombardy, Italy. Ann Intern Med. 2020;173(5):405-7. https://doi.org/10.7326/M20-1447.

32. Kimball A, Hatfield KM, Arons M, James A, Taylor J, Spicer K, et al. Asymptomatic and Presymptomatic SARS-CoV-2 infections in residents of a long-term care skilled nursing facility - King County, Washington, march 2020. MMWR Morb Mortal Wkly Rep. 2020;69(13):377-81.

33. Arons MM, Hatfield KM, Reddy SC, Kimball A, James A, Jacobs JR, et al. Presymptomatic SARS-CoV-2 infections and transmission in a skilled nursing facility. N Engl J Med. 2020;382(22):2081-90. https://doi.org/10.1056/ NEJMoa2008457.

34. Sofia S, Boccatonda A, Montanari M, Spampinato M, D'Ardes D, Cocco G et al. Thoracic ultrasound and SARS-COVID-19: a pictorial essay. J Ultrasound. 2020;23(2):217-21. https://doi.org/10.1007/s40477-020-00458-7.

\section{Publisher's Note}

Springer Nature remains neutral with regard to jurisdictional claims in published maps and institutional affiliations.

Ready to submit your research? Choose BMC and benefit from:

- fast, convenient online submission

- thorough peer review by experienced researchers in your field

- rapid publication on acceptance

- support for research data, including large and complex data types

- gold Open Access which fosters wider collaboration and increased citations

- maximum visibility for your research: over $100 \mathrm{M}$ website views per year

At BMC, research is always in progress.

Learn more biomedcentral.com/submissions 